Commentary

\title{
Ku circles the telomere?
}

\section{Christian Sell}

\section{Department of Pathology, Drexel University College of Medicine, Philadelphia, PA}

\author{
Commentary on: Li et al. Depletion of Ku70/80 reduces the levels of extrachromosomal telomeric circles and inhibits \\ proliferation of ALT cells. Aging 2011;3: this issue \\ Received: 4/25/11; Accepted: 4/26/11; Published: 4/26/11 \\ Corresponding to: christian.sell@drexelmed.edu \\ (C) Sel. This is an open-access article distributed under the terms of the Creative Commons Attribution License, which permits unrestricted \\ use, distribution, and reproduction in any medium, provided the original author and source are credited
}

Not all tumor cells are created equal when it comes to telomere biology. Tumor cells that do not express telomerase appear to utilize a telomerase-independent process to maintain telomere length, known as ALT for alternative lengthening of telomeres [1]. Although the existence of this process has been recognized for some time, the precise mechanism by which telomeres are maintained in these cells has been difficult to determine [2]. A recent report introduces a new element into the ALT story, implicating the $\mathrm{Ku} 70 / 80$ protein heterodimer (simply referred to as $\mathrm{Ku}$ ) in the ALT process. Work reported by $\mathrm{Li}$ and coworkers in this issue of Aging, reveals a novel requirement for $\mathrm{Ku}$ in maintaining telomeres in immortal cells that utilize ALT [3]. The authors present data using a gene targeting approach to deplete both $\mathrm{Ku}$ subunits in two independent ALT cell lines. The ALT cells succumb to a combination of senescence and apoptosis without loss of telomere length or single-stranded telomere overhang. Surprisingly, the production of extra chromosomal DNA circles (t-circles) is reduced following $\mathrm{Ku}$ depletion as it is following depletion of MRE11/NBS1, known requirements for t-circle formation [4]. The results are striking because the $\mathrm{Ku}$ heterodimer is a central element in the nonhomologous end joining (NHEJ) DNA repair pathway, as it binds preferentially to free DNA ends and functions to recruit components of NHEJ DNA repair such as DNAdependent protein kinase (DNAPK) and ligase IV. Although the $\mathrm{Ku}$ heterodimer is intimately involved in DNA repair, it has become apparent that $\mathrm{Ku}$ also participates in a wide variety of functions related to genome integrity. For example, $\mathrm{Ku}$ has been localized to origins of replication, and has been implicated in chromatin remodeling required for transcriptional activation and in telomere maintenance [5]. $\mathrm{Ku}$ also appears to play a role in aging. Deletion of the $\mathrm{Ku} 80$ gene leads to an immune-deficient phenotype due to loss of proper VDJ recombination, but also induces a premature aging phenotype [6]. Ku 80 levels and DNA end binding also show a striking exponential correlation with species lifespan [7], suggesting that increased $\mathrm{Ku}$ function is requisite for long-lived species. Additionally, $\mathrm{Ku}$ levels decrease during replicative senescence [8]. Consistent with a higher requirement for $\mathrm{Ku}$ function in long-lived species, $\mathrm{Ku}$ appears to play an essential role in human cells while it is dispensable in rodent cells [9]. $\mathrm{Ku}$ has also been identified as a nodal point in systems analysis of aging-related DNA repair genes [10]. The $\mathrm{Ku}$ heterodimer is required for proper telomere function in multiple species, but the precise requirement for $\mathrm{Ku}$ seems to depend upon the specific telomere biology of the species [11]. Nonetheless, $\mathrm{Ku}$ appears to be an essential element of the protein complex that forms at the telomere. $\mathrm{Ku}$ is required for proper telomere maintenance in normal human cells and in telomerase positive cells $[9,12]$. Interestingly, the role for $\mathrm{Ku}$ differs in each of these settings. In normal human fibroblasts, a reduction in $\mathrm{Ku}$ induces a rapid senescence combined with a decreased binding of a key telomere binding protein, TRF2, to the chromatin. In telomerase positive tumor cells, apoptosis is induced. Most surprising is the contrasting effect of $\mathrm{Ku}$ targeting on the t-circles that are diagnostic of the ALT mechanism [13]. Depletion of Ku in telomerase positive cells leads to the production of $\mathrm{t}$-circles while the work of $\mathrm{Li}$ et al. demonstrates that depletion of $\mathrm{Ku}$ in ALT cells leads to a reduction in t-circles. In normal human fibroblasts $\mathrm{Ku}$ appears to be critical to proper cell cycle progression as cells rapidly senesce following $\mathrm{Ku}$ depletion. This rapid senescence likely precludes the development of either the t-circle formation or telomere 
fusions seen in the immortal cells. A different scenario occurs in ALT cells. In these cells, it appears that $\mathrm{Ku}$ has been incorporated into the mechanism responsible for t-circle production, leading to their reduction following $\mathrm{Ku}$ depletion. What is the common denominator between these cell types linking $\mathrm{Ku}$ function to telomere function? One possibility is the association between $\mathrm{Ku}$ and core telomere-associated proteins such as TRF2. Ku 70 has been found to directly interact with TRF2 [14]. TRF2 appears to function as a hub for the formation of specific protein complexes at the telomere [15] and the interaction between TRF2 and $\mathrm{Ku}$ may be important to prevent NHEJ at the telomere [16]. Depletion of Ku leads to reduced TRF2 binding to chromatin [12], suggesting that Ku may stabilize TRF2mediated protein complexes. Given that altering TRF2 function influences t-circle formation [17], it may also be that $\mathrm{Ku}$ influences TRF2 protein complexes at the telomere that are necessary for t-circle formation. In addition, the structural characteristics of telomerasepositive and ALT telomeres likely differ, providing another potential explanation for the differential roles for $\mathrm{Ku}$ in t-circle formation. A greater understanding of the precise mechanisms involved will require additional experimentation, however, the work by $\mathrm{Li}$ and coworkers provides striking evidence that $\mathrm{Ku}$ serves very specific roles at the telomere that can vary as the telomere biology varies, even in human cells, and suggests that in at least a subset of ALT cell lines, $\mathrm{Ku}$ is involved in the resolution of the telomere-induced genomic crisis that these cells have undergone during their clonal evolution.

\section{REFERENCES}

1. Bryan TM, Englezou A, Gupta J, Bacchetti S, Reddel RR. Telomere elongation in immortal human cells without detectable telomerase activity. EMBO J. 1995;14:4240-4248.

2. Cesare AJ, Reddel RR. Alternative lengthening of telomeres: models, mechanisms and implications. Nature Rev Genet. 2010;11:319-330.

3. Li B, Reddy S, Comai L. Depletion of Ku70/80 reduces the levels of extrachromosomal telomeric circles and inhibits proliferation of ALT cells. Aging (Albany NY). 2011; 3: this issue.

4. Compton SA, Choi JH, Cesare AJ, Ozgur S, Griffith JD. Xrcc3 and $\mathrm{Nbs} 1$ are required for the production of extrachromosomal telomeric circles in human alternative lengthening of telomere cells. Cancer Res. 2007;67:1513-1519.

5. Downs JA, Jackson SP. A means to a DNA end: the many roles of Ku. Nature Rev Mol Cell Biol. 2004;5:367-378.

6. Vogel H, Lim DS. Karsenty G, Finegold M, Hasty P. Deletion of Ku86 causes early onset of senescence in mice. Proc Natl Acad Sci USA. 1999;96:10770-10775.

7. Lorenzini A, Johnson FB. Oliver A, Tresini, M, Smith JS. Hdeib $M$, Sell C, Cristofalo VJ, Stamato TD. Significant correlation of species longevity with DNA double strand break recognition but not with telomere length. Mech Aging Dev. 2009;130:784-792.
8. Seluanov A, Danek J, Hause N, Gorbunova V. Changes in the level and distribution of Ku proteins during cellular senescence. DNA Repair. 2007;6:1740-1748.

9. Wang $Y$, Ghosh G, Hendrickson EA. Ku86 represses lethal telomere deletion events in human somatic cells. Proc Natl Acad Sci USA. 2009;106:12430-12435.

10. Freitas AA, Vasieva $O$, de Magalhaes JP. A data mining approach for classifying DNA repair genes into ageing-related or non-ageing-related. BMC Gen. 2011;12:27.

11. Fisher TS, Zakian VA. Ku: a multifunctional protein involved in telomere maintenance. DNA Repair. 2005;4:1215-1226.

12. Fink LS, Lerner CA, Torres PF, Sell C. Ku80 facilitates chromatin binding of the telomere binding protein, TRF2. Cell Cycle. 2010;9:3798-3806.

13. Henson JD, Cao Y, Huschtscha LI, Chang AC, Au AY, Pickett HA, Reddel RR. DNA C-circles are specific and quantifiable markers of alternative-lengthening-of-telomeres activity. Nature Biotech. 2009;27:1181-1185.

14. Song K, Jung D, Jung $Y$, Lee SG, Lee I. Interaction of human Ku70 with TRF2. FEBS. 2000;481:81-85.

15. Kim H, Lee OH, Xin H, Chen LY, Qin J, Chae HK, Lin SY, Safari A, Liu D, Songyang Z. TRF2 functions as a protein hub and regulates telomere maintenance by recognizing specific peptide motifs. Nature Struct Mol Biol. 2009;16:372-379.

16. Celli GB, Denchi EL, de Lange T. Ku70 stimulates fusion of dysfunctional telomeres yet protects chromosome ends from homologous recombination. Nature Cell Biol. 2006;8:885-890.

17. Li B, Jog SP, Reddy S, Comai L. WRN controls formation of extrachromosomal telomeric circles and is required for TRF2DeltaB-mediated telomere shortening. MCB. 2008;28:18921904. 